\title{
O Festival de Filosofia de Abrantes (Portugal)
}

The Philosophy Festival of Abrantes (PoRTUGal)

\author{
JosÉ ALVES JANA \\ Universidade de Coimbra \\ jalvesjana@gmail.com
}

O Festival de Filosofia de Abrantes (Portugal) realizou em novembro de 2018 a sua segunda edição. O grande objectivo do Festival pode dizer-se como um serviço da Filosofia à cidade, chamando-a a pensar um problema importante com que a mesma cidade se defronta.

Em 2017, na estreia, o tema escolhido foi "O regresso da História: A crise da democracia e o autoritarismo; a religião e os radicalismos". Depois do anúncio do "fim da História" e da "vitória" da democracia liberal, os problemas voltaram e agora a democracia está em perda, ao mesmo tempo que os radicalismos religiosos parecem ameaçar os próprios fundamentos de uma cidade que, por ser de todos e para todos, se quer (ainda?) neutra face às religiões organizadas.

Em 2018, o tema foi também de primeira atualidade: “A inteligência artificial, o trabalho e o humano: automação e organização do trabalho; o primado do instrumental ou o primado do humano". A inteligência artificial (IA) está aí, cheia de promessas, mas também de ameaças, tanto às pessoas singulares, na perspetiva de um desemprego endémico, como à própria espécie, agora considerada descartável a favor de um próximo passo evolutivo, a máquina muito mais inteligente e eficaz que os complicados e mais ou menos inúteis humanos. É para aí que caminhamos? É para aí que queremos ir?

Para falar destes temas, foram convidados especialistas capazes de abrir uma reflexão com pistas de análise diversas, pois é evidente 
que numa sociedade complexa não se vai longe com um pensamento fechado.

O Festival de Filosofia de Abrantes propõe-se ser um lugar de encontro entre perspetivas diversas, um espaço interdisciplinar capaz de desafiar os participantes a irem mais longe do que iriam se pensassem sozinhos. Por isso, os filósofos e os sociólogos, os politólogos e os engenheiros, os físicos e os homens e mulheres de religião, os políticos e os cidadãos anónimos conseguiram criar um ambiente que ia para lá de cada um dos participantes. O que interessa não é tanto o que cada um disse, mas o espaço teórico e prático "entre" todos, a fim de que o problema se afirme e as análises se desenvolvam.

Trata-se, portanto, de um serviço da Filosofia à cidade, à polis que juntos formamos e na qual queremos ser agentes ativos e (um pouco mais) esclarecidos. O Festival não é um lugar de encontro de especialistas, mas das pessoas comuns entre si e com os especialistas convidados. A cidade é dos cidadãos e é a estes que cabe a responsabilidade do destino coletivo. Para que o possam fazer de forma mais inteligente, é importante debater os problemas com que se confrontam. Daí que o Festival não pretende ser tanto algo que acontece "na" cidade, mas algo que tem a cidade por sujeito. É difícil, não é um adquirido, mas é a direção para onde se quer caminhar. Implica, por isso, pensar como é que a cidade pode ser "picada" pelo moscardo a fim de despertar para o problema e como é que ela pode dar passos no sentido de uma maior inteligência das coisas. A estratégia escolhida foi plural, diversificada. Desde logo o espaço-tempo de reflexão com convidados que despertassem o apetite, mas também outras formas de presença e estímulo: uma feira do livro temática e apresentação de livros, teatro e música, um café filosófico, poesia na rua e instalação poética na praça da cidade, filosofia com crianças e jovens nas escolas, frases nas ruas e um espaço de intervenção livre para jovens ("palete da liberdade") do tipo do Speakers' Corner em 
Londres. E ainda um concurso nacional de ensaio para jovens do ensino secundário. E ainda a presença com crónicas e outras intervenções na comunicação social local (rádio e jornais) e mesmo nacional. E ainda...

Uma das formas de levar a cidade a fazer o seu Festival é unir várias entidades na sua realização: câmaras municipais e associações culturais, escolas e outras organizações trabalham em conjunto para que o Festival aconteça, mesmo que problemas de comunicação e organização tornem a parceria por vezes mais um objetivo a alcançar que um facto adquirido.

O Festival é de Filosofia. Desde logo afirma a Filosofia na cidade. Mas afirma-a não como uma disciplina académica na sua especificidade técnica, mas como uma presença qualificada na vida da cidade. Trata-se, portanto, de trazer a Filosofia à cidade e de levar a cidade à Filosofia, não contra outras especialidades disciplinares, mas como um exercício de pensar crítico sobre a vida que em conjunto queremos levar, para a qual cada área disciplinar tem contributos a dar. O Festival é, por isso e desde logo, um objeto filosófico, se assim se pode dizer. E é-o também na medida em que afirma o apelo a cada pessoa e organização a pensar de modo crítico. "Todo o ser humano é filósofo" e qualquer organização encarna uma filosofia. Não admira que a Filosofia tenha um lugar na cidade e que possa ser exercida de modo ativo por cada ator social, com maior ou menor formação filosófica e crítica. O diagnóstico é conhecido: a Filosofia migrou para a Academia e, por isso, na praça da cidade sente-se a falta de um Sócrates e de tantos outros filósofos maiores. Há, então, que contar com os filósofos comuns que habitam e fazem a cidade. O festival de Filosofia de Abrantes também é isso. Por isso pretende-se dar a palavra - escutar! - as pessoas que fazem a cidade, a começar pelos jovens. Um dos painéis do programa foi, em cada edição, constituído por jovens do ensino secundário, "jovens filósofos" que têm uma palavra a dizer. E disseram. E valeu a pena ouvi-los. 
Também os mais velhos, hoje com mais ou menos especialização, começaram por ser jovens e pensar então o tempo que era o seu. Os jovens de hoje vivem num tempo que é também seu e são protagonistas da e na cidade. É caminhando que se faz o caminho (A. Machado).

Quando se reúnem pessoas de diversas religiões e outros sem pertença religiosa, quando se encontram pessoas de diversas áreas disciplinares, quando participam pessoas de diversa opção política, é inevitável que o encontro seja também desencontro. Que o que é dito por um seja recusado por outro. Que o que agora é evidente seja depois negado ou recusado. Não é um defeito, é o feitio desejado. Também por isso o Festival é um objeto filosófico no sentido de ser um espaço-tempo em que pessoas de alinhamentos e pertenças diversas e até opostas podem com-viver sem terem de concordar, podem afirmar o que pensam e serem ouvidas e respeitadas, podem mostrar o que pensam sem por isso serem agredidas. Não se trata de eliminar as tensões sociais, mas de criar um espaço e um tempo de diálogo (dia logos) "entre" os lugares da diferença. Não para anular as diferenças, mas para as entendermos e aprendermos com elas. Não vamos resolver os problemas do mundo? Não construímos ali uma ordem de trabalho político coerente e sistemático? Também não é essa a missão do Festival. Mas quem participa de forma continuada não sai na mesma, sai diferente, mesmo que apenas um pouco. O Festival faz parte, não é o todo, nem o mestre da cidade, não pretende sê-lo.

Um dos temas do Festival é a presença da Filosofia na cidade, isto é, fora da Academia. Como se faz? Quem faz? Onde se faz? Temos de aprender uns com os outros. Na segunda edição, por exemplo, uma sessão foi explicitamente dedicada a este tema. A participação ao vivo das Olimpíadas de Filosofia do Rio de Janeiro (Brasil), do Clube de Filosofia do Porto e do Clube de Filosofia de Abrantes e por vídeo a consultoria filosófica em prisões e não só na área de Sevilha mostraram diversas formas de trabalho filosófico na 
cidade. Precisamos todos de aprender uns com os outros e de experimentar novas formas de presença filosófica na vida das pessoas, das organizações e das comunidades. Se é vasto o património filosófico herdado, é também vasta e diversa a história da participação ativa da Filosofia enquanto trabalho por dentro das formas de vida. Mas, já acima fica dito, a Filosofia tem-se mantido um pouco acantonada na Academia e a olhar sob suspeita, se não mesmo com um certo ostracismo, toda a forma filosófica extraescolar, salvo a atividade editorial. Ora o Festival de Filosofia é a afirmação em ato de que a cidade precisa da Filosofia, quer a Filosofia e acolhe bem a Filosofia, quando esta consegue perceber que a cidade não é a Academia, que a comunicação filosófica na cidade não é do mesmo tipo que na Academia, que o próprio exercício filosófico na cidade não pode ser do mesmo tipo que na Academia.

Isto coloca problemas complexos, é evidente. Tanto aos filósofos comprometidos na cidade como à Academia. O que ainda é e o que já não é Filosofia? Qual a diferença entre uma simples tertúlia e um encontro de natureza filosófica? O que pode ser exigido em contexto académico a uma intervenção e o que já não é justo que se exija à intervenção de um cidadão comum que se atreve a pensar com outros? As respostas são complexas, mas sempre respaldadas com o facto significativo de que a Filosofia é por natureza, e por isso sempre o foi de facto, plural. Isso não deve permitir baixar o cuidado e a exigência com as práticas filosóficas não académicas, mas também não é filosófico confundir como mesmo o que é diverso. A Filosofia na cidade não pode copiar a Academia. Mas também não pode - nem quer - ignorá-la. Desde logo porque os filósofos que operam na cidade fizeram e voltam a fazer a sua formação na Academia, embora não só. Depois, porque os filósofos da Academia também são chamados a participar da vida filosófica na cidade. No Festival Filosófico de Abrantes essa participação verificou-se já, pelo menos, de duas formas: o convite a filósofos 
académicos a participarem dos trabalhos e a venda e apresentação de livros de produção mais académica. Contudo, as modalidades a explorar vão, sem dúvida, muito para lá disso, mas dependem também da disponibilidade e da criatividade da própria Academia. Por isso, a própria existência do Festival é um desafio à Academia: que outras formas de participação são possíveis e desejáveis? Como é que a Academia pode ser parceira nessa presença ativa da Filosofia na cidade?

No entanto, é importante tomarmos consciência de que é fácil dizer, mas é bem mais difícil fazer. Ao escrever, pode dar-se a falsa ideia de que a cidade se mobilizou e foi, ela mesma no seu conjunto, o sujeito do Festival. De facto, as organizações e as pessoas que fizeram o Festival são parte da cidade, mas não são a cidade toda. O Festival não se propõe ser um fenómeno de massas, quer ser fermento na massa, sementeira com vontade de que venha a frutificar. Não há por detrás qualquer projeto de um rei-filósofo. A cidade pertence aos cidadãos e são eles, e as suas organizações, que são chamados ao exercício da Filosofia.

\section{O Clube de Filosofia de Abrantes}

Foi o Clube de Filosofia de Abrantes (CFA) que fez à Câmara local a proposta de realização de um festival de filosofia. Aceite a proposta, o Clube é um dos parceiros nos trabalhos de conceção, programação e concretização do Festival.

Constituído em 2012 por quatro professores formados em Filosofia e já aposentados, que pensaram que podiam e deviam fazer algum trabalho filosófico na sua cidade, o CFA é uma organização informal, sem personalidade jurídica, mas com uma ação que se mantém há seis anos.

Começou a sua atividade com um ciclo em que convidou todos os partidos políticos com assento na Assembleia Municipal a virem 
falar com os seus concidadãos sobre o que andavam a fazer. Mais tarde, um outro ciclo chamou os presidentes de Câmara a, igualmente, virem dar conta do que andavam a fazer. A ideia, em ambos os casos, foi a mesma: afirmar a importância do trabalho político e focar a atenção na cidade. Era o mote para a importância de pensar e discutir a vida que fazemos em comum. E tem sido, justamente, esse o programa do CFA: ajudar as pessoas a pensar. "Pensar entre nós" é o lema do Clube.

O primeiro ciclo de "café filosófico" foi dedicado a pensar as palavras que usamos sem pensar no dia a dia. Que dizemos quando dizemos crise, poder, consciência, jogo, energia, pessoa, competição, felicidade, ideologia, cidade, decisão, autoridade, sistema, verdade, caos e tantas outras? A certa altura, alterou-se um pouco o figurino: em vez de uma palavra, o tema era uma afirmação: "se Deus morreu, tudo é permitido", "ser é ser percebido", "Deus é uma ideia da Razão"... Concordo ou discordo? e porquê?

Uma das preocupações do Clube de Filosofia tem de ser o património filosófico e os seus atores maiores. Sentiu-se, por isso, necessidade de trazer a público, um público não constituído por pessoas de filosofia, alguns filósofos, tanto clássicos como da atualidade mais recente. Passaram a ter lugar nos cafés filosóficos, embora com um maior poder de palavra ao apresentador. Foi assim que por ali passaram Tales de Mileto, Parménides, Descartes, Kant, Hegel, entre outros, mas também Wittgenstein, Karl Popper, John Rawls, M. Sandel... E o que começou por ser quase uma obrigação de filósofos, acabou por traduzir-se em sessões que as pessoas, para surpresa dos organizadores, muito apreciaram.

O método adoptado foi sempre o mesmo, excepto na apresentação dos filósofos: um convidado abre a sessão durante mais ou menos vinte minutos e depois o diálogo segue "entre" os presentes, com cada um a poder usar da palavra e com direito a ser ouvido. Isso traz o benefício de deslocar o poder do lugar do orador para o 
espaço entre os presentes. Mas traz também a limitação de, não havendo um lugar de poder, correr-se o risco de tudo ser igualmente válido. Sócrates não tem lugar ali. Qual é a diferença entre um café dito filosófico e uma tertúlia de café? É um problema que importa ter presente e procurar, para ele, uma solução. Uma das vias de solução é o papel que os membros do Clube são chamados a exercer, embora não tenham uma palavra privilegiada, a não ser que a sua clarividência a imponha. Mas não é verdade que todos sabemos pensar? Bem, os interlocutores de Sócrates também o pensavam.

A certa altura, dois convites ao Clube vieram diversificar as linhas de trabalho. Uma associação da cidade desafiou o Clube a retomar a apresentação e debate de livros: passou a ser o "café com letras". E de um município vizinho, a Câmara convidou o Clube a fazer alguma coisa no centro cultural local: para não repetir o que já se fazia, apostou-se na ideia de "voltar" aos livros que, sendo clássicos, é suposto termos lido, porque fizeram uma civilização, mas não tivemos ainda vagar de ler: é o "Voltar aos Clássicos". Isso levou a que o "café com letras" se passasse a dedicar mais ao livro de ensaio com tema de atualidade.

E são estas três linhas de trabalho que têm vindo a estruturar a atividade do Clube de Filosofia de Abrantes: "Café Filosófico" sujeito a tema, "Café com Letras" a partir de um livro de atualidade e "Voltar aos Clássicos" a partir de um livro clássico.

Além destas três frentes continuadas da programação, outras iniciativas pontuais ou extraordinárias têm sido levadas a efeito. Foi o Clube de Filosofia de Abrantes que na região assinalou os centenários da edição da "Utopia", de Tomas Morus, e das "95 teses de Lutero". Esta última sessão, por exemplo, reuniu num painel um católico, um luterano e um calvinista, o que cria um acontecimento que, localmente, só parece pensável, por isso realizável, no contexto do Clube de Filosofia. Uma sessão destas cria, desde logo, um lugar filosófico em que o "encontro" (que não 
é o mesmo que fusão sincretista) entre compromissos de vida pode ter lugar e ser apreciado por todos os participantes, incluindo os não crentes.

Em 2016, o Clube de Filosofia de Abrantes decidiu apresentar à autarquia local a proposta de um festival de Filosofia. Aceite a proposta, o Clube passou a ser parte da parceria para levá-lo a efeito. Já acima fica dito. Mas além do trabalho com outros na produção do Festival, o Clube tem assumido uma outra parte de sua responsabilidade: preparar e dar continuidade ao tema, isto é, a reflexão do Festival. Para o Festival de 2017, o fundamentalismo islâmico, que estava na ordem do dia, exigia desbravar um pouco a ignorância não assumida sobre o mundo islâmico. Por isso foram programadas três sessões: "Maomé", "O Corão" e "Islamismo". Quem acompanhou as sessões chegou ao Festival já mais capaz de entender e discutir as várias intervenções então feitas pelos convidados. O mesmo se passou em 2018: quatro sessões fizeram o mesmo trabalho de preparação: "1984", de George Orwell, "Técnica e ciência como ideologia", de Jürgen Habermas, "Manifesto Comunista", de Karl Marx, e "La Révolution transhumaniste", de Luc Ferry.

Mas há pessoas para discutir essas coisas? Bem, no ano de 201718, de setembro a julho, as 26 sessões tiveram 531 participantes, portanto numa média de 20 participantes por sessão. É um trabalho de pesca à linha, em que as pessoas só voltam se sentirem que valeu a pena.

Importa ainda dizer que os membros do Clube vêm mantendo alguma presença filosófica a título pessoal nas redes sociais, sobretudo no Facebook. Ali veiculam informação e problematização de natureza filosófica. Também na rádio local a Filosofia está presente através dos seus contributos individuais. Estas outras dimensões do trabalho filosófico contribuem para a presença continuada da Filosofia na cidade e para a cidade se 
aproximar da Filosofia e receber dela alguns contributos para que uma "vida refletida" seja cada vez melhor vivida.

Entretanto, um dos quatro membros do Clube deixou pouco depois o núcleo do projeto, mas há poucos meses uma jovem filósofa passou a integrar o grupo.

E agora? Além de estar já, com os parceiros, a preparar o Festival de Filosofia de 2019, o Clube de Filosofia de Abrantes continua a procurar novas formas e novos métodos de "trazer a Filosofia à cidade e a cidade à Filosofia". Ainda recentemente procedeu à "leitura integral" e "em voz alta" do "Êutifron", de Platão, seguida de debate entre os presentes. E os níveis de satisfação manifestados foram talvez superiores às expectativas. Há ainda outras modalidades a explorar, além de que o Clube e os frequentadores mais habituais estão empenhados em procurar apurar o método de gestão das sessões de modo a superar a simples tertúlia de café e elevar o nível filosófico do nosso trabalho comum. Porque não se trata de os filósofos da cidade pregarem filosofia à cidade, mas de, importa repeti-lo, "trazer a Filosofia à cidade e a cidade à Filosofia". 


\section{RESEÑAS BIBLIOGRÁFICAS REVIEWS}


